\title{
The workers role in knowledge management and sustainability policies
}

\author{
Ivan Bolis ${ }^{*}$, Claudio Brunoro and Laerte Idal Sznelwar \\ Production Engineering department, Universidade de São Paulo, Av. Prof. Almeida Prado, Travessa 2, $N^{o} 128$, \\ São Paulo, Brazil.
}

\begin{abstract}
Based on the concepts of sustainability and knowledge management, this article seeks to identify points of contact between the two themes through an exploratory study of existing literature. The first objective is to find, in international literature, the largest number of papers jointly related to the theme of knowledge management and sustainability. In these documents, the authors looked at the kind of relationship existing between the two themes and what the benefits introduced in organizations are. Based on an ergonomic point of view, the second objective of this article is to analyze the role of the worker (whether at the strategic or operational level) and his importance in this context. The results demonstrate that there is very little literature that addresses the two themes together. The few papers found, however, can be said to show the many advantages of introducing sustainability policies supported by adequate knowledge management. Very little has been studied with regards to the role of workers, which could be interpreted as meaning that little importance is given to the proactive role they may play. On the other hand, there is a high potential for future research in these areas, based on the high level of consideration of workers in knowledge management and sustainability literature, as well as in literature in the areas of ergonomics and sociology.
\end{abstract}

Keywords: knowledge management, sustainability, worker

\section{Introduction}

The last several years have been characterized by an explosion in the theme of sustainability and by an increase in the importance of the theme of knowledge in companies. Concomitantly, workers are also gaining growing consideration and the management of work within the organization is becoming a strategic issue for business success. Based on these premises, the article presented here intends to identify these themes' points of contact through an exploratory study of the existing bibliography. There are two main research questions: how are joint studies on the theme of sustainability and knowledge management (KM) evolving, and what are their relative contributions? Using the articles found in the literature as a point of departure, the importance of workers for the success of sustainability policies through the management of their knowledge (and if so, which) is analyzed.

\section{Theoretical reference}

Below the themes of sustainability, knowledge management, ergonomics and organizational action are introduced separately. All of these themes are disciplines with specific literatures and are distinct from one another.

\subsection{Sustainability}

The word "sustainable" is derived from the Latin "sustinēre" and expresses defense, the maintenance of life, and in 1972, in the Stockholm conference, was used for the first time in an international forum to discuss the relationship between man and the environment.

Since this event, sustainability has become a central term in the entire debate on the major questions of our future. One of the most well-known definitions was published in 1987 in the report on the Independent United Nations Commission chaired by then-

\footnotetext{
${ }^{*}$ Corresponding author. E-mail: bolis.ivan@yahoo.it.
} 
Norwegian Prime Minister Gro Harlem Brundtland: "Humanity has the ability to make development sustainable to ensure that it meets the needs of the present without compromising the ability of future generations to meet their own needs." Adding on to this, Coomer [4] describes the "sustainable society is one that lives within the self-perpetuating limits of its environment. That society is not a 'no growth' society. It is rather, a society that recognizes the limits of growth [and] looks for alternative ways of growing $[4, \mathrm{p} .1]$." In this definition, Coomer identifies the fact that there is a primary aspect, the environmental aspect, based on which only successively may all of the other aspects (social, economic and political) function. Based on this perspective, the vision of the ecological economy $[3,20]$ is put forth, defining sustainability when one considers that the economy is a sub-series of society, and society a sub-series of our planetary ecological system.

With a different vision of the ecological economy, companies' actions today are oriented towards what is defined as the "Triple Bottom Line - TBL," in which sustainability is found at the intersection between distinct concerns in the environmental, economic and socio-cultural dimensions [11]. The main concept of TBL demands that a company's responsibility be directed at all stakeholders, instead of being directed exclusively at shareholders [35]. In this case, "stakeholder" refers to anyone who is influenced, directly or indirectly, by the company's actions. According to this theory, then, the business entity should be used as a vehicle to coordinate the interests of all parties, rather than exclusively maximizing the profit of shareholders (owners).

Based on the concept of TBL, in addition to the environmental and economic aspect, the sociocultural aspect takes on importance as well. Dividing this last dimension into issues outside the company (care with the surrounding community, for example) and those internal to it, care with workers and their working conditions falls in to the latter category.

\subsection{Knowledge management}

Knowledge is very relevant to companies. Drucker [10] described it as the only significant resource of our time, while Toffler [33] defined it as the source of all economic powers. Knowledge has been receiving a great deal of attention because of the increase in competition, the turbulent context and innovation, which leads knowledge to be seen as a resource (intellectual capital) that must be managed like econom- ic resources, people and raw materials. There are, however, a number of critical points in Knowledge Management: there are challenges due to the continuous introduction of new technologies; knowledge belongs to the knowledge workers and not to organizations [10]; it is hard to share and capitalize on what is known; and, finally, knowledge quickly becomes obsolete if it is not developed and discussed continuously. Based on this, a systematic effort is necessary in order to find, organize and make available the intellectual capital the organization needs, in addition to nourishing a culture of continuous learning and a sharing of knowledge.

According to Nonaka and Takeuchi [25], there are two dimensions to be considered: the nature of knowledge and where it resides (in the individual, in the group, in the organization and in the interorganizational dimension). Considering the first dimension, one can distinguish between explicit and formal knowledge, which can be codified and transmitted in the organization by way of documents, and tacit knowledge, based on personal experience and on subjective awareness and which encompasses practical abilities, individual experiences and creative solutions. Also according to Nonaka and Takeuchi [25], the forms of interaction between tacit knowledge and explicit knowledge (and, as a consequence, between the individual and the organization as well) result in four processes of the conversion of knowledge that make up the SECI (spiral of knowledge) model. Knowledge then passes from the individual to the group, to the organization, and vice-versa through continuous cycles of socialization, externalization, combination and internalization. In order to favor these processes, organizations' management may use different levers of intervention, specific to that discipline, denominated "knowledge management." Knowledge management may thus be identified as the series of organizational mechanisms, management policies and information technologies through which the company stimulates and influences the behavior of individuals and groups in terms of the assimilation and generation, transfer and sharing, capitalization and re-utilization of knowledge, in its explicit or tacit form, useful in pursuing the organization's goals. Knowledge management generally refers to all efforts at improving and increasing the value of the generation, sharing and application of knowledge [8].

The objective of companies is to become "learning organizations" - in other words, organizations that acquire, create and efficiently transfer knowledge in an effective way within the company, and alter their 
activities so as to reflect new knowledge and new abilities [18].

The worker gains importance in knowledge management because his participation is fundamental [30], having an active posture in the process of the construction of knowledge: "Work is no longer the series of tasks descriptively associated with the job, but has become the direct prolongation of the competencies the individual mobilizes in the face of a more changeable and complex professional situation $[17, \mathrm{p}$. 54]."

Also according to Thomke and Reinersten [31], people are of major importance for knowledge management to create competitive advantages, being that it is in them, and not in physical resources, that knowledge is rooted, such that this knowledge is not easily imitated. As such, companies need to think about the importance and significance of the people management dimension [28].

\subsection{The contributions of ergonomics and of Maggi's Organizational Action theory}

Centered on the theme of work [1], ergonomics is recognized as an autonomous discipline, but which needs to be nourished from the acquisitions of other disciplines in an interdisciplinary spirit $[14,35]$. The objective of this discipline is to "transform work so as to adapt it to the characteristics and variability of man and the productive process [1, p. 19]." In the phase of ergonomic analysis, as described by Falzon [14] and Daniellou [6], it is necessary to attain positive results in two main spheres, at times in tension with one another: one centered on the organization and on its performance (in terms of productivity, efficiency, reliability, quality, etc.), and the other centered on people (in terms of safety, health, comfort, ease of use, well-being, etc.).

There exist two main methodological approaches, the Ergonomic Work Analysis (EWA) and the Human Factors (HF) approach. The EWA proposes to analyze work situations with the objective of adapting work to man, based on the analysis of the activity in real situations, while HF also proposes to adapt work, albeit focusing more on tasks. One of the fundamental concepts of EWA is precisely the discussion of the discrepancy between the prescribed and the real, distinguishing the concepts of task and activity. "The task is what should be done, that which the organization prescribes. The activity is what is done, what the subject mobilizes of himself to carry out the task [14]." This is because, based on the variability of real work situations, workers elaborate original strategies to attend to the tasks prescribed by organizations through their knowledge about the work [19]. This worker knowledge is of great importance because it can help identify flaws in processes and deal with events. Based on this knowledge, ideas may emerge either for the improvement of worker wellbeing or for performance and business performance. For this, companies can take advantage of this knowledge and this flow of information derived from work situations through the implementation, for example, of an improvement committee. Obviously all of this requires a social construction in which the company's various different workers on the various different hierarchical levels are involved.

With a different approach, Bruno Maggi comes to the same conclusion. Through the logic of organizational action [23], he explains that the organized work system is a process of decisions and actions aimed at expected objectives and results. The logic of organizational action and of the system as a process is based on the idea of "intentional and bounded rationality," which at the same time guides the process with regards to objectives and values; each element in the process is variable because it is the fruit of choices. Knowing that each element of the process is correctible and modifiable (as are the objectives), one may carry out projections and corrections of these elements in order to reduce constraints and to ensure preferential processes of well-being. Acknowledging the fact that workers have direct knowledge about their own work, the best way to reduce constraints (that is, when the organization removes some of the individual's decision-making autonomy) is to act in favor of worker emancipation, so that workers may have greater influence on decisions about their work and the construction of their health. In the same direction as improvements in health, the introduction of sustainability policies should make it possible to reduce this constraint in order to ensure preferential states of well-being. With this, a strategic alignment is possible, with these people being the ones most responsible for making sustainability policies viable. Otherwise, these people are unable to achieve the objectives of sustainability [23]. The involvement of people requires the creation of spaces in which they can strengthen cooperation and deliberation on workrelated issues. 


\section{Research propositions}

Sustainability and knowledge management are two themes that have had a considerable impact in recent years, and little is discussed regarding possible relations in their joint implementation. For exploratory purposes, the first proposition may be introduced:

P1: In the literature, little is discussed about the possible links and the benefits that may be achieved in a joint introduction of policies of sustainability and of improvements in knowledge management.

Based on the literature, it is clear how policies of sustainability and improvement in knowledge management may be introduced in organizations and can act simultaneously without causing incompatibilities. What had to be verified is if there are additional benefits that could derive from the linking of these two themes in the organization's strategic policies. In particular, it is believed that sustainability strategies lead to benefits if integrated as improvement policies in knowledge management. The second proposition to be confirmed is the following:

P2: An aspect that should be considered for success in the introduction of strategic policies of sustainability in organizations is the presence of an accurate management of knowledge.

After all, introducing sustainability policies in companies is a strategic choice made by the directorship, but one that has practical impacts on the change in processes and work throughout the organization. The adequate top-down management of information is necessary to ensure the application of strategic sustainability policies.

As such, although workers are traditionally considered simple executors of such directives, based on a perspective in line with the ideas of ergonomics and of Maggi, policies can only be successful depending on these workers' actions. In addition to needing to gain relevance in order to remain motivated, they should be considered as active and useful subjects. The consideration of information made available by workers can allow for greater effectiveness in the strategic decisions of sustainability themselves. Following this line of argument, it is thus possible to introduce the third proposition:

P3: failing to consider the knowledge of workers when sustainability strategies are implemented would mean not taking advantage of a flow of information and knowledge that, from the bottom up, would permit alignment between policies and practical actions of sustainability, an alignment that is essential for a company to obtain success.

\section{Methodology}

The methodology used for this article was, in an initial phase, bibliographical research, followed by the analysis of the contents of all of the articles found. In the bibliographical research, an option was made to seek articles through the data bases present on the Internet and on international literature, making it possible to gather the results of multidisciplinary studies without regard to geographic location. In this first phase, major attention was given to the choice of the data base so as to allow for the reading of the largest possible number of articles on the subjects in question, while at the same time taking works from major international journals. After various attempts, the final choice fell upon the Scopus base from SciVerse. On April 18, 2011, through a search for the terms "knowledge management" and "sustainability," we found 192 documents. Given that this number is reasonable, it was not necessary to subsequently narrow down the search with other terms, but out of the total documents encountered, only the articles (17) were considered.

After a quick bibliometric study, a second phase of the research consisted of reading all of the articles with the objective of understanding what the relationship between the two themes investigated was, and if there is a transfer of worker knowledge that can assist in the upgrading of sustainability policies.

\section{Results}

As was mentioned in the previous chapter, through a joint bibliographical search of the terms "knowledge management" and "sustainability," we found 117 articles. Based on the reading of all of the articles, it became clear from the very beginning that not all of them directly focused on the two themes investigated. In particular, there are many texts that insert the term "knowledge management" between the key words themselves as a generic term and not as a discipline that encompasses a series of strategies and practices. Knowledge management is sometimes also used in summaries to indicate the generic management of information among people. As for the term "sustainability," there were also many cases (more than with knowledge management) in which it was not used in accordance with what was defined in the chapter on the literature. In many texts, sustainability is used as a (generic) adjective for other words, without being connected to specific themes on future 
impacts. To these cases, we may also add articles in which the main themes approached are neither knowledge management nor sustainability. Excluding the analysis of such articles from the second phase, a total of 49 articles remained for study.

Through this initial phase of the reading and selection of the most important articles according to their finality, it was possible to extract some bibliometric information. In figure 1, one may observe the number of articles published per year found by way of the search of the two terms. The blue line on the graph represents the total number of articles found, and the red line the articles that went on to be analyzed in the second phase. It must be mentioned that in 2011, the values were multiplied by three due to the fact that the search took place in April (based on the hypothesis that articles would be published over the next eight months at the same rate as during the first four months of the year). Analyzing the magazines from which all of the articles were taken, it was verified that the sources were heterogeneous, with 17 of the magazines represented with two articles, and only one, the Journal of Clean Production, represented by four articles.

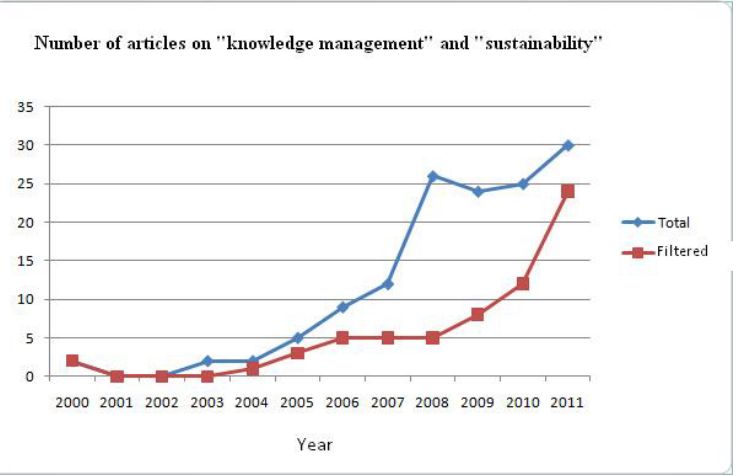

Figure 1 - Number of article on "knowledge management" and "sustainability"

Focusing attention exclusively on the 49 texts selected, through a reading of each one of them, it was possible to introduce an analysis on their content. In particular, the articles were studied according to five parameters: typology of sustainability, scope of the term knowledge management, the typology in which the discussion is situated, the area of application of the themes, and, finally, the degree of relevance and inter-relatedness of the two themes.

In the 49 articles analyzed, the term sustainability was not always used in its full meaning, as presented in the TBL. Of all of the articles, only 12 discuss sustainability with this meaning, while another 21 discuss the environmental side of sustainability, two discuss the social side and one the economic side. There are, however, 13 articles in which it was difficult to define in what spheres the term sustainability was inserted; many of these articles speak of sustainable development, which is often associated with an exclusively environmental sustainability.

Analyzing the theme of knowledge management, 19 of the texts discuss the theme in its entirety, while 27 articles discuss just one of its aspects, and three articles discuss it in a rather shallow manner.

In the analysis of the typology in which the discussion is situated, 16 articles deal with aspects related to companies' strategic policies, 14 are theoretical in nature, 7 discuss processes, 7 discuss tools, 4 discuss specific projects and cases, and, lastly, one discusses products.

The area of application of the themes is not specific (i.e., it remains generic) in 10 articles. In 12, the construction industry is discussed, in 10 other types of industries are discussed, in seven environmental problems in a future perspective, in four the relationship between academic knowledge and real-life application, in three energy issues, and in three technology.

Analyzing the articles in their degree of relevance and inter-relatedness between the two themes that were the object of the article, it was possible to divide the articles into four main groups:

- 24 articles that present the two themes as relevant and with a very accentuated relationship with one another,

- 6 articles that present the two themes as relevant and with a limited relationship with one another,

-1 article that presents the two themes as relevant, but without contact with one another,

- 18 articles that present the two themes on differentiated levels of relevance, in which one is a function of the other.

Entering into the specificities of the results and of the discussions obtained by all of the articles, it was possible to identify those that show how major benefits can be obtained with the introduction of sustainability policies that include knowledge management. In general, adequate knowledge management can allow companies to manage all of the knowledge that is being built upon sustainability, a new theme that can lead to major competitive advantages if well administered, in a more satisfactory way. Alongside this are articles that individualize sustainability, or 
the need to act in an environment in which there are ecological and environmental links, such as a simple increase in the system's complexity, and as such individualize the application of knowledge management as opportunities to minimize the effects of an increase of this complexity [2, 9, 12, 29].

The articles that deal with sustainability in the widest sense of the term (TBL, but also as sustainable development), which present knowledge management in its integrity and which were classified as belonging to the first group in the degree of relevance and inter-relatedness of the two themes in question, total 14.

Analyzing the role developed by workers and based on the 49 articles, very little is discussed. The texts discuss the application of sustainability and knowledge management policies with an almost exclusively top-down direction in the organization. There are articles, for example, that discuss the importance of the role of leaders or of decision-makers in organizations $[7,24]$, of specialists and important stakeholders [22, 32, 34] and of academia (students) in the introduction of real policies [5].

Of the 49 articles, only five make explicit the importance of worker knowledge in the operational area. Three of these see these workers as captors of useful information [16, 21, 27] and one sees them as users of a system introduced by a city administration as intellectual capital to reach objectives of sustainability [26]. The last of these articles, one of the two that discuss sustainability with an almost exclusively social focus, shows the relationships between human behavior, the perfecting of knowledge, and the success of sustainability policies [12].

\section{Discussion}

Starting with the first research proposition, few of the articles found truly discuss the possible links and benefits that may be achieved in the joint introduction of the themes of sustainability and knowledge management. This was confirmed by the bibliographical search, which did not require further refinement with additional terms, and by the low number of articles analyzed (49), of articles that present both themes as relevant and having a very relevant relationship between one another (24), or of articles that present the themes of knowledge management and sustainability in the full sense of the term and identify them as having major relevance (14). The bibliometric study made it clear that the link between the two themes is quite recent, with a noticeable increase in the number of articles having occurred beginning in 2009. In reference to figure 1 , the difference between the two lines in the years 2008-2009 may indicate that beginning in those two years the theme of sustainability gained importance and a consequent presence in articles. This indicates, then, that the theme has major growth potential and that real research opportunities exist, as well as in the niche of joint application alongside knowledge management. The fact that the sources of the articles were heterogeneous further indicates the amplitude of the fields of research in which the two themes have the potential to be studied jointly.

The analysis of the content of the articles demonstrated that the second proposal also makes sense - in other words, that an aspect to be considered for the successful introduction of strategic sustainability policies in organizations is the presence of accurate knowledge management. This affirmation gains even more weight considering the fact that most of the articles found were strategic and theoretical in nature, and came mainly from the construction industry, in which the potential for gain with the theme of sustainability is very well recognized [37]. The amplitude of the application of the two themes, present in various areas of application and in different typologies in which the discussion is situated, should also be considered for the analysis of this proposition. The main results of the analysis of 14 articles, presented in table 1 , is an example of how extensive the contact between the two themes can be and how many benefits can derive from this.

The case of the presence of a great deal of articles related to the construction industry, to environmental problems and to the energy issue identifies how the main motor for sustainability is, in many situations, the ecological-environmental aspect, in which knowledge management is introduced mainly to resolve problems (currently, in the case of market sensitiveness to such issues, and, in the future, because of their ecological impacts) in a reactive posture. On the other hand, there are various articles, mostly of the strategic type, that see the introduction of knowledge management that supports sustainability policies with the objective of obtaining competitive advantages in a proactive way. It would be expected that these articles could focus greater attention on the role of workers, seeing them as a differential in order to achieve the objectives themselves. Based on the results, very few indications were given on workers, such that the third proposition, also based on a vision 
of ergonomics and of social sciences with Maggi, was unable to be confirmed.

\section{Conclusions}

The article presented here contributes in showing how little the themes of knowledge management and sustainability have been jointly studied up to the present. Despite this, in the past several years, a growing number of articles have investigated this niche of knowledge, and the few articles found already demonstrate very positive results of the effectiveness of sustainability policies through the use of accurate knowledge management.

The article also shows how the contributions of workers for the success of such policies have been given very little attention in the available literature. This fact stands in contrast with the concepts of knowledge management and sustainability introduced, which show us firstly that knowledge originates in people, and, consequently, that in order to ensure full sustainability it is necessary for companies to take responsibility for internal social aspects as well. Based on the ergonomic and sociological thinking put forth by Maggi, workers should be involved in order to permit an increase in the performance of organizations, in addition to greater wellbeing for the subjects. It is believed, then, that studies in this niche are not numerous because the expected results are underestimated. As such, new studies are needed, focusing on the role of workers in the perspective of sustainability.

In this phase, it is pertinent to highlight a major limitation of the present article. Although the selection of the data base was well planned, the analysis of the texts allowed for the extraction of qualitative data which can be interpreted and classified in a subjective manner by the authors. Despite this, we believe the global results to be completely valid.

\section{References}

[1] Abrahão, J.; Sznelwar, L.I.; Silvino, A.; Sarmet, M. PINHO, D. Introdução à ergonomia da prática à teoria. São Paulo: Blucher, 2009.

[2] Butler, T. Compliance with institutional imperatives on environmental sustainability: Building theory on the role of Green IS. Journal of Strategic Information Systems, 20(1), pp. 6-26, 2011

[3] Common, M. and Sigrid S. Ecological Economics: An Introduction. Cambridge University Press, Cambridge, U.K, 2005.
[4] Coomer, J. The Nature of the Quest for a Sustainable Society. In J. Coomer (Ed.), Quest for a Sustainable Society. Oxford: Pergamon Press, 1979.

[5] Cummins, V. and McKenna, J. The potential role of Sustainability Science in coastal zone management. Ocean and Coastal Management, 53(12), pp. 796-804, 2010.

[6] Daniellou, F. A ergonomia em busca de seus princípios: debates epistemológicos. São Paulo, Edgar Blucher, 2004.

[7] David, R. and McKenna, B. Knowledge, wisdom and intellectual leadership: A question of the future and knowledge-based sustainability. International Journal of Learning and Intellectual Capital, 6(1-2), pp. 52-70, 2009.

[8] Dawson, R. Knowledge capabilities as the focus of organizational development and strategy, Journal of Knowledge Management, Vol. 4 No. 4, pp. 320-7, 2000.

[9] Demaid, A. and Quintas, P. Knowledge across cultures in the construction industry: Sustainability, innovation and design. Technovation, 26(5-6), pp. 603-610, 2006.

[10]Drucker, P.F. Management challenges for the 21st century. Harper Business; 1999.

[11]Elkington, J. Towards the sustainable corporation: Winwinwin business strategies for sustainable development. California Management Review 36, no. 2, pp 90-100, 1994.

[12]Faber, N., Jorna, R. and Van Engelen, J. The sustainability of "sustainability" - A study into the conceptual foundations of the notion of "sustainability". Journal of Environmental Assessment Policy and Management, 7(1), pp. 1-33, 2005.

[13]Faber, N.R., Peters, K., Maruster, L., Van Haren R. and Jorna, R. Sense making of (Social) sustainability: A behavioral and knowledge approach. International Studies of Management and Organization, 40(3), pp. 8-22, 2010.

[14]Falzon, P. Ergonomia. São Paulo, Edgard Blucher, 2007.

[15]Felton, S.M. Knowledge is Capital, The Rest is Just Money, Strategy \& Leadership, 30, \#3, pp. 41-42, 2002.

[16]Fernandez -Gimenez, M.E. and Knapp, C.N. Understanding change: Integrating Rancher knowledge into state-andtransition models. Rangeland Ecology and Management, 62(6), pp. 510-521, 2009.

[17]Fleury, M. T. L. A Gestão de Competência e Estratégia Organizacional. In: Fleury, M. T. L. (Org) As Pessoas na Organização. São Paulo: Gente, 2002.

[18] Garvin, D.A. Building a Learning Organization. In Harvard Business Review on Knowledge Management. Harvard Business School Press, pp. 47-80, 1998.

[19] Guérin, F; et al., Compreender o trabalho para transformá-lo: a prática da ergonomia. São Paulo: Edgard Blücher, 2001.

[20]Herman, E.D. and Joshua F. Ecological Economics: Principles and Application, Island Press, Washington DC, 2004.

[21]Knapp, C.N. and Fernandez-Gimenez, M.E. Knowledge in practice: Documenting rancher local knowledge in Northwest Colorado. Rangeland Ecology and Management, 62(6), pp. 500-509, 2009

[22] Kraines, S. and Guo, W. A system for ontology-based sharing of expert knowledge in sustainability science. Data Science Journal, 9, pp. 107-123, 2011

[23] Maggi, B. Do agir organizacional: um ponto de vista sobre o trabalho, o bem-estar, a aprendizagem. São Paulo: Edgard Blucher, 2006.

[24] Mohamed, M., Murray, A. and Mohamed, M. The role of information and communication technology (ICT) in mobilization of sustainable development knowledge: A quantitative evaluation. Journal of Knowledge Management, 14(5), pp. 744-758, 2010

[25]Nonaka, I.; Takeuchi, H. The Knowledge Creating Company. University Press, Oxford, 1995. 
[26] Ortiz -Fournier, L.V., Márquez, E., Flores, F.R., RiveraVázquez, J.C. and Colon, P.A. Integrating educational institutions to produce intellectual capital for sustainability in $\mathrm{Ca}$ guas, Puerto Rico. Knowledge Management Research and Practice, 8(3), pp. 203-215, 2010.

[27]Reed, M.S., Buenemann, M., Atlhopheng, J., Akhtar Schuster, M., Bachmann, F., Bastin, G., Bigas, H., Chanda, R., Dougill, A.J., Essahli, W., Evely, A.C., Fleskens, L., Geeson, N., Glass, J.H., Hessel, R., Holden, J., Ioris, A.A.R., Kruger, B., Liniger, H.P., Mphinyane, W., Nainggolan, D., Perkins, J., Raymond, C.M., Ritsema, C.J., Schwilch, G., Sebego, R., Seely, M., Stringer, L.C., Thomas, R., Twomlow, S. and Verzandvoort, S. Cross-scale monitoring and assessment of land degradation and sustainable land management: A methodological framework for knowledge management. Land Degradation and Development, 22(2), pp. 261-271, 2011.

[28]Robertson, M. and Hammersley, G.M. Knowledge management practices within a knowledge-intensive firm: the significance of the people management dimension, Journal of European Industrial Training, Vol. 24 No. 2, pp. 241-53, 2000.

[29] Söderberg, H. and Kain, J. Assessments of sustainable waste management alternatives: How to support complex knowledge management. Journal of Environmental Planning and Management, 49(1), pp. 21-39, 2006.
[30] Theriou, G.N. and Chatzoglou, P.D. Enhancing performance through best HRM practices, organizational learning and knowledge management: A conceptual framework. In: European Business Review. V. 20, I.3, 2008.

[31] Thomke, S. and Reinertsen, D. Agile product development: managing development flexibility in uncertain environments. California Management Review, v. 41, n. 1, p. 8-30, Fall 1998.

[32] Thomson, C.S., El-Haram, M.A. and Emmanuel, R. Mapping knowledge flow during sustainability assessment. Proceedings of the Institution of Civil Engineers: Urban Design and Planning, 163(2), pp. 67-78, 2010

[33] Toffler, A. Powershift: Knowledge, Wealth and Violence at the Edge of the 21st Century, Batam Books, New York, 1990.

[34] Trotta, M.G. Product lifecycle management: Sustainability and knowledge management as keys in a complex system of product development. Journal of Industrial Engineering and Management, 3(2), pp. 309-322, 2010.

[35] Tuttle, T. and Heap, J. Green productivity: moving the agenda. International Journal of Productivity and Performance Management, 57(1), 93-106, 2008.

[36] Wisner, A. Antropotecnologia. Rio de Janeiro, 2004.

[37]Zavadskasa, E.K., Kaklauskas, A., Vainiunas, P. and Saparauskasc, J. A model of sustainable urban development formation, International Journal of Strategic Property Management, Volume 8, Issue 4, 2004, Pages 219 - 229, 2004. 